\begin{tabular}{lcr}
\multicolumn{3}{c}{ ANNALES } \\
UNIVERSITATIS MARIAE CURIE-SKŁODOWSKA & \\
& LUBLIN - POLONIA & \\
VOL. LXXIII, 1 & SECTIO AA & 2018 \\
\hline
\end{tabular}

\title{
Synthesis and characterization of linear and crosslinked polymers with the addition of DMSPS
}

\author{
Karolina Fila* and Beata Podkościelna \\ Department of Polymer Chemistry, Faculty of Chemistry, \\ Maria Curie-Skłodowska University, \\ Gliniana 33, 20-614 Lublin, Poland \\ *e-mail: karolina.fila@poczta.umcs.lublin.pl
}

\begin{abstract}
The aim of this research was the synthesis of polymers with the addition of S,S'-thiodi-4,1-phenylene bis(thiomethacrylate) (DMSPS) by bulk polymerization. Styrene (St), divinylbenzene (DVB) and ethylene glycol dimethacrylate (EGDMA) were used for the copolymerization as main monomers. The chemical structures of sulfur-containing polymers were confirmed by the spectroscopic analysis (ATR/FT-IR). In order to determine the impact of the sulfur derivative (DMSPS) addition on thermal properties of the obtained copolymers, differential scanning calorimetry (DSC) was performed. The hardness tests of the obtained copolymers were also applied using a Shore durometer.
\end{abstract}

Keywords: sulfur-containing polymers, bulk polymerization, thermal analysis, hardness test

\section{INTRODUCTION}

Bulk polymerization belongs to the basic types of polymerization techniques and generally involves a monomer/monomers and an initiator as the main components, without a solvent. The initiator should be dissolved in the liquid monomer/monomers [1-5]. The 
reaction can be initiated by heating or exposing to UV radiation. The obtained polymers assume the shape of the reaction vessel for this reason bulk polymerization is useful in the production of cast-molded products. This reaction is exothermic and the real problem concerns the dissipation of the heat produced by polymerization. Additionally, this method leads to the products with very broad molecular weight distribution. Bulk polymerization is used for manufacturing many polymers such as polystyrene, polyethylene, polymethyl methacrylate, and many others $[6,7]$.

In the literature, many reports on polymers with controlled structure and molecular weights can be found. Block copolymers are a specific class of copolymers in which chemically different monomer units are grouped into separate blocks along the polymer chain [8]. Owing to the advancement of strategies and techniques of polymer synthesis, e.g. controlled polymerization techniques, block copolymers with accurately controlled molecular weights and defined macromolecular structures can be obtained [9-11]. Over the last two decades, the range of applications for block copolymers has rapidly expanded into the fields of advanced materials (e.g., thermoplastic elastomers), drug delivery, patterning, porous materials, electro optics, compatibilization of polymer blends, and many others $[12,13]$.

Over the past few years significant advances have been made in the field of living or controlled free radical polymerization such as atom transfer radical polymerization (ATRP) [14-16], reversible addition fragmentation transfer polymerization [17-20], and nitroxide-mediated radical polymerization [21-23]. Among these techniques, ATRP has been successfully used in the preparation of various styrene [24], acrylate [25], and methacrylate [26] monomers. Block copolymers composed of segments with different functional properties were synthesized [27]. Although anionic polymerization is an excellent method to produce block copolymers, it is technically difficult and not compatible with the electrophilic or acidic functional groups. Free radical polymerization can be also used for various vinyl monomers. Recently, ATRPs reported by Wang et al. [28] and Kato et al. [29] were used for the copolymerization of styrene with BA, [30] MMA with BA, [31] styrene with MMA and MMA with n-butyl methacrylate [32].

In this paper a sulfur-containing monomer (DMSPS) was used to obtain bulk copolymers with different structures. The polymerization 
course was confirmed by the attenuated total reflection-Fourier transform infrared (ATR/FT-IR) spectroscopy. The physico-chemical properties of the obtained polymers, including the thermal properties (DSC) and the hardness tests were studied.

\section{EXPERIMENTAL}

\subsection{Materials}

Divinylbenzene (DVB) and $\alpha, \alpha^{\prime}$-azoisobisbutyronitrile (AIBN) were obtained from Merck (Darmstadt, Germany). S,S'-thiodi-4,1phenylenebis(thiomethacrylate) (DMSPS) and ethylene glycol dimethylacrylate (EGDMA) were purchased from Sigma-Aldrich (Sweden). Styrene (St) was obtained from Avantor Performance Materials (Gliwice, Poland). All chemicals were used as received.

\subsection{Bulk polymerization of DMSPS with commercial monomers}

A bulk polymerization method was used to obtain the sulfur copolymers [33]. The main used monomers were styrene (St), divinylbenzene (DVB), and ethylene glycol dimethylacrylate (EGDMA). The sulfur derivative of S,S'-thiodi-4,1-phenylenebis(thiomethacrylate) (DMSPS) was used as an active additive. The initiator of this reaction was $\alpha, \alpha^{\prime}$-azoisobisobutyronitrile (AIBN). The copolymerization was carried out in glass tubes in a water bath at $65^{\circ} \mathrm{C}$ for $20 \mathrm{~h}$ and then continued for $4 \mathrm{~h}$ at $80^{\circ} \mathrm{C}$. The linear and crosslinked polymers were obtained. In order to compare physical and chemical properties, homopolymers of St, DVB, and EGDMA were also made. Table 1 lists the amounts of chemicals used for the copolymerization. The chemical formulae of monomers are shown in Fig. 1.

Table 1. The amounts of substrates used in copolymerization.

\begin{tabular}{cccc}
\hline \multicolumn{2}{c}{ DMSPS } & \multicolumn{3}{c}{$\begin{array}{c}\text { St (or DVB or } \\
\text { EGDMA), g }\end{array}$} & $0.5 \%$ AIBN, g \\
\cline { 1 - 2 }$\%$ & $\mathrm{~g}$ & 2 & 0.01000 \\
0 & - & 2 & 0.01005 \\
1 & 0.01 & 2 & 0.01010 \\
5 & 0.02 & 2 & 0.01050 \\
\hline
\end{tabular}


<smiles>C=C(C)C(=O)Sc1cccc(Sc2cccc(SC(=O)C(=C)C)c2)c1</smiles>

DMSPS<smiles>C=Cc1ccccc1</smiles><smiles>C=Cc1ccc(C=C)cc1</smiles><smiles>C=C(C)C(=O)OCCOC(=O)C(=C)C</smiles>

DVB

EGDMA

Fig. 1. The monomers used in bulk polymerization.

\subsection{Measurement methods}

Attenuated total reflection-Fourier transform infrared (ATR/FTIR) spectra were obtained with a FTIR TENSOR 27 (Bruker, Germany) spectrophotometer using finely crushed materials. The spectra were recorded from 4000 to $700 \mathrm{~cm}^{-1}$ averaging 32 scans with a resolution of $4 \mathrm{~cm}^{-1}$.

Differential scanning calorimetry (DSC) tests were performed with a Netzsch 204 calorimeter (Germany). All DSC measurements were taken in aluminium pans with pierced lids (mass of $40 \pm 1 \mathrm{mg}$ ). As a reference, empty aluminium crucible was applied. Sample masses of about $10 \mathrm{mg}$ were used. The scans were performed at the heating $/$ cooling rate of $10^{\circ} \mathrm{C} / \mathrm{min}$ in the nitrogen atmosphere (flow $=$ $\left.30 \mathrm{~cm}^{3} / \mathrm{min}\right)$. Glass transition temperatures $\left(T_{g}\right)$, enthalpy of decomposition $\left(\Delta H_{d}\right)$, initial $\left(T_{\text {onset }}\right)$, final $\left(T_{\text {offset }}\right)$, and maximum $\left(T_{\text {peak }}\right)$ temperatures of decomposition for the polymer samples were taken.

The hardness of the obtained copolymers was measured by the Shore D method on a Zwick 7206/H04 hardness tester (Germany) at $22^{\circ} \mathrm{C}$. The values were taken after $15 \mathrm{~s}$. 


\section{RESULTS AND DISCUSSION}

\subsection{The ATR/FT-IR analysis}

The ATR/FT-IR spectra of the St-homo and its copolymers are shown in Fig. 2.

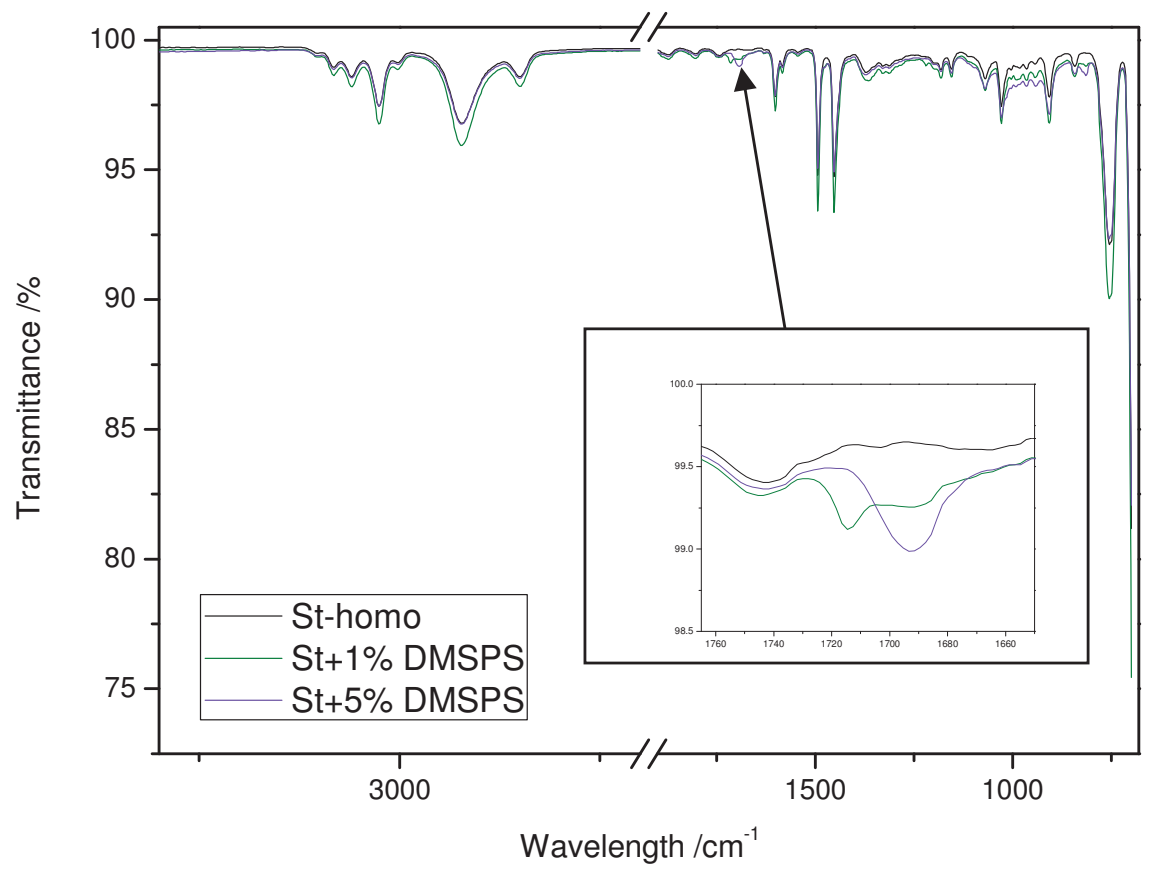

Fig. 2. The ATR/FT-IR spectra of St-homo and its copolymers with DMSPS.

Generally, similar absorption bands are present in all spectra. However, for the copolymers (St+1\%DMSPS and St+5\%DMSPS) the appearance of the characteristic vibrations of the carbonyl group (1690 and $1694 \mathrm{~cm}^{-1}$ ) (bands in magnification) was observed. The presence of carbonyl groups (derived from the methacrylate unit) indicates the incorporation of the DMSPS monomer into the structure of the resulting copolymers. This confirms the planned course of copolymerization processes. However, due to the small amount of DMSPS additive, the intensity of the signals is not large.

The same conclusions follow from the spectra of DVB-homo and its copolymers shown in Fig. 3. 


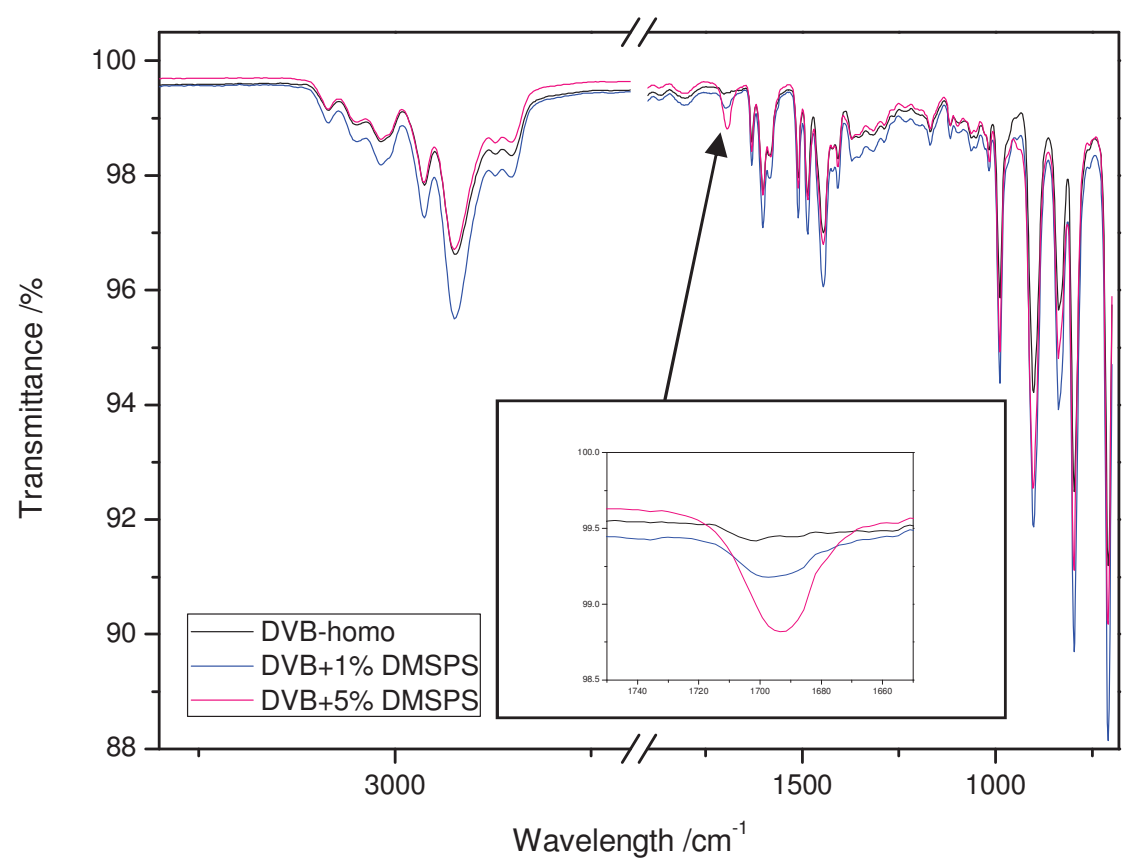

Fig. 3. The ATR/FT-IR spectra of DVB-homo and its copolymers with DMSPS.

The ATR/FT-IR spectra of the EGDMA-homo and its copolymers (EGDMA+1\%DMSPS and EGDMA+5\%DMSPS) are shown in Fig. 4.

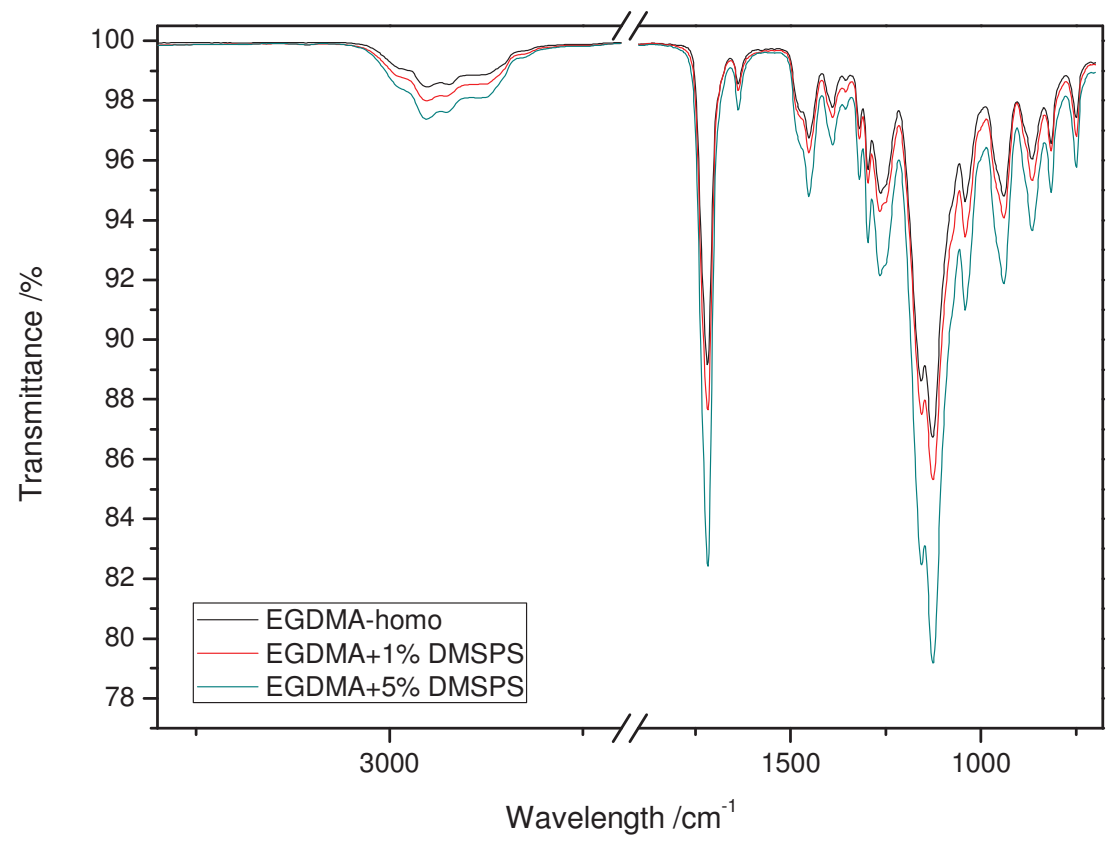

Fig. 4. The ATR/FT-IR spectra of EGDMA-homo and its copolymers with DMSPS. 
The spectra show the occurrence of similar signals which differ slightly in the intensity of bands. In the spectra absorption of C-O-C group gives a strong peak at $1127 \mathrm{~cm}^{-1}$. The aromatic skeletal absorption is observed at 1452 and $1637 \mathrm{~cm}^{-1}$. The signal of $\mathrm{C}=0$ group occurs at $1718 \mathrm{~cm}^{-1}$. The stretching vibrations bands of vinyl groups $(\mathrm{C}-\mathrm{H})$ are seen at $940 \mathrm{~cm}^{-1}$ and for methyl groups $(\mathrm{C}-\mathrm{H})$ at $2952 \mathrm{~cm}^{-1}$. The $\mathrm{C}-\mathrm{H}$ bands are observed at 1296 and $1319 \mathrm{~cm}^{-1}$. The signal at $749 \mathrm{~cm}^{-1}$ can be assigned to the Ar-H vibrations.

\subsection{Thermal properties of the obtained polymers}

Thermal properties of the selected polymers were studied by means of DSC analysis. The DSC curves of copolymers with 5\% addition of DMSPS are presented in Fig. 5. The characteristic parameters from the DSC curves are given in Table 2. On the curves, one endothermic effect connected with the thermal degradation is visible at $437^{\circ} \mathrm{C}$ for DVB $+5 \%$ DMSPS and at $406^{\circ} \mathrm{C}$ for St $+5 \%$ DMSPS. Additionally, on the curve small exothermic effect at $190-200^{\circ} \mathrm{C}$ is noticeable. This effect is typical of DVB copolymers and related to the crosslinking reaction. On the other hand, two endothermic peaks are observed for the EGDMA+5\%DMSPS. The first peak at $325^{\circ} \mathrm{C}$ is probably related to the distribution of network fragments derived from the EGDMA monomer. The second endothermic peak at $431^{\circ} \mathrm{C}$ is caused by the decomposition of the crosslinked part of the copolymer. The values of enthalpy of decomposition $\left(\Delta H_{d}\right)$ are in the range 161-722 J/g depending on the type of monomer used in the copolymerization. For St+5\%DMSPS, the glass transition temperature $\left(T_{g}\right)$ was also determined, which was $106^{\circ} \mathrm{C}$. The DSC analysis leads to the conclusion that the obtained copolymers with the addition of DMSPS are characterized by good thermal resistance.

Table 2. The results of the DSC analysis.

\begin{tabular}{cccccc}
\hline Sample & $\begin{array}{c}T_{g} \\
{\left[{ }^{\circ} \mathrm{C}\right]}\end{array}$ & $\begin{array}{c}T_{\text {onset }} \\
{\left[{ }^{\circ} \mathrm{C}\right]}\end{array}$ & $\begin{array}{c}T_{\text {peak }} \\
{\left[{ }^{\circ} \mathrm{C}\right]}\end{array}$ & $\begin{array}{c}T_{\text {offset }} \\
{\left[{ }^{\circ} \mathrm{C}\right]}\end{array}$ & $\begin{array}{c}\Delta H_{d} \\
{[\mathrm{~J} / \mathrm{g}]}\end{array}$ \\
\hline St+5\%DMSPS & 106 & 336 & 406 & 430 & 722 \\
DVB+5\%DMSPS & - & 380 & 437 & 470 & 313 \\
EGDMA+5\%DMSPS & - & 180 & 325 & 359 & 537 \\
& & 359 & 431 & 460 & 161 \\
\hline
\end{tabular}




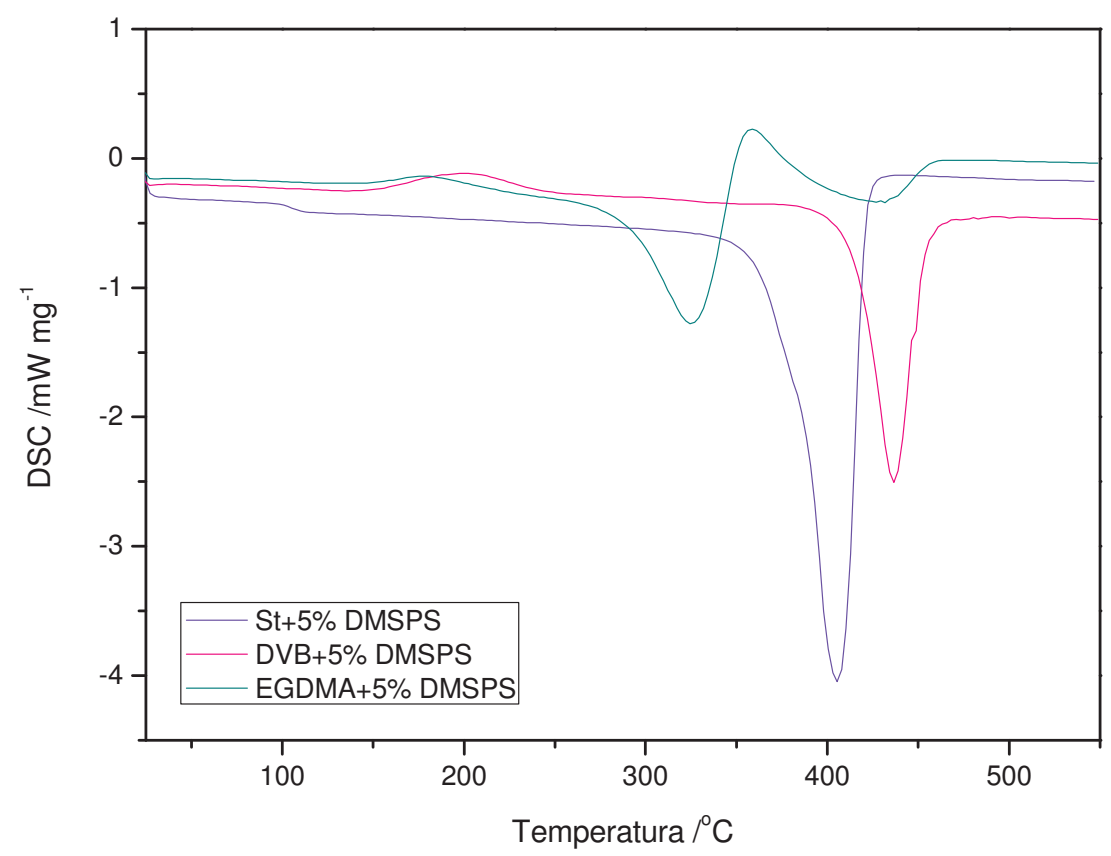

Fig. 5. DSC curves of copolymers with 5\% addition of DMSPS.

\subsection{Evaluation of hardness of the obtained copolymers}

The results of the hardness tests are shown in Table 3 . The highest value of hardness was exhibited by the EGDMA+5\%DMSPS copolymer while the lowest value was assigned to the DVB homopolymer. These results are a consequence of chemical structures of the obtained polymers. The larger addition of DMSPS in the copolymer, the higher the hardness.

Table 3. The hardness of polymers measured in the Shore scale, D.

\begin{tabular}{cc}
\hline Name of sample & Hardness, ${ }^{\circ} \mathrm{Sh}$ \\
\hline St-homo & 77 \\
St+0.5\%DMSPS & 78 \\
St+1\%DMSPS & 79 \\
St+5\%DMSPS & 83 \\
DVB-homo & 74 \\
DVB+0.5\%DMSPS & 76 \\
DVB+1\%DMSPS & 80 \\
DVB+5\%DMSPS & 81 \\
EGDMA-homo & 82 \\
\hline
\end{tabular}




\begin{tabular}{cc}
\hline EGDMA+0.5\%DMSPS & 82 \\
EGDMA+1\%DMSPS & 83 \\
EGDMA+5\%DMSPS & 86 \\
\hline
\end{tabular}

\section{CONCLUSIONS}

As a result of bulk polymerization, linear (St-DMSPS) and crosslinked (DVB-DMSPS and EGDMA-DMSPS) polymers were obtained. Spectroscopic analysis confirmed the proper course of copolymerization reactions with the addition of DMSPS and the presence of chemical vibrations from the groups, including $v(\mathrm{Ar}-\mathrm{H})$, $v\left(\mathrm{CH}_{3}\right), v(\mathrm{C}=\mathrm{O}), \mathrm{C}=\mathrm{C}_{\mathrm{Ar}}, \delta(\mathrm{CH}), \delta\left(\mathrm{C}_{\mathrm{Ar}}-\mathrm{H}\right)$. The DSC method proved the thermal resistance of the tested materials to high temperatures. These materials are stable up to $325^{\circ} \mathrm{C}$. Generally, one can conclude that the DVB copolymer has a higher thermal stability than the St and EGDMA copolymers. The hardness of the obtained polymers was tested showing that the EGDMA copolymers are characterized by the highest hardness.

\section{REFERENCES}

[1] N. P. Cheremisinoff, in: Condensed Encyclopedia of Polymer Engineering Terms, $B$, Butterworth-Heinemann, 32-38, (2001).

[2] C. E. Carraher, in: Polymer Chemistry, 6th Edition, Chapter 8,CRC Press LLC, New York, (2003).

[3] R. O. Ebewele, in: Polymer Science and Technology, Chapter 10, CRC Press LLC, New York, (2000).

[4] P. B. Zetterlund, H. Yamazoe, B. Yamada, D.J.T. Hill, P.J. Pomery, Macromolecules, 34, 7686, (2001).

[5] N. K. Tien, E. Flaschel, A. Renken, Chem. Eng. Commun., 36, 251, (1985).

[6] Y. Suzuki, D. S. Cousins, Y. Shinagawa, R. T. Bell, A. Matsumoto, A. P. Stebner, Polym. J., 51, 423, (2019).

[7] I. W. Hamley, in: The Physics of Block Copolymers, Vol. 19, Oxford University Press, New York, USA, (1998).

[8] N. Hadjichristidis, H. Iatrou, M. Pitsikalis, J. Mays, Prog. Polym. Sci., 31, 1068, (2006).

[9] D. Uhrig, J. W. Mays, J. Polym. Sci. A: Polym. Chem., 43, 6179, (2005).

[10] H. Zhang, K. Hong, J.W. Mays, Macromolecules, 35, 5738, (2002).

[11] H. C. Kim, S. M. Park, W. D. Hinsberg, Chem. Rev., 110, 146, (2009). 
[12] H. Feng, X. Lu, W. Wang, N. G. Kang, J. W. Mays, Polymers, 9, 494, (2017).

[13] E. H. Riddle, Monomeric Acrylic Esters, Rohm \& Haas Company, Philadelphia, 29-39 (1954).

[14] V. Percec, F. J. Asgarzadeh, J. Polym. Sci. A: Polym. Chem., 39, 1120, (2001).

[15] X. X Kong, T. Kawai, J. Ake, T. Iyada, Macromolecules, 34, 1120, (2001).

[16] M. Husseman, E. E. Malmstrom, M. McNamara, M. Mate, D. Mecerreyes, D. G. Benoit, J. L. Hedrick, P. Mansty, E. Huang, T. P. Russell, C. J. Hawker, Macromolecules, 32, 1424,(1999).

[17] J. S. Wang, K. Matyjaszewski, Macromolecules, 28, 7572, (1995).

[18] S. Xia, K. Matyjaszewski, Macromolecules,30, 7692, (1997).

[19] S. Zhu, D. Yan, G. J. Zhang, J. Polym. Sci. A: Polym. Chem.,39, 765, (2001).

[20] G. Moineau, H. Dubois, R. Jerome, T. Senninger, P. H. Teyssie', Macromolecules, 31, 545, (1998).

[21] T. Tsoukatos, S. Pispas, N. J. Hadjichristidis, J. Polym. Sci. A: Polym. Chem., 39, 320,(2001).

[22] D. Benoit, C. J. Hawker, E. E. Huang, Z. Q. Lin, T. P. Russell, Macromolecules, 33, 1505,(2000).

[23] S. Buts, H. Baethge, G. Schmidt-Naake, Macromol. Chem. Phys., 201, 2143, (2000).

[24] M. Destarac, J. M. Bessiere, B. J. Boutevin, J. Polym. Sci. A: Polym. Chem., 36, 2933, (1998).

[25] C. J. Hawker, E. Elce, J. Dao, W. Volksen, T. P. Russell, G. G. Barclay, Macromolecules, 29, 2686,(1996).

[26] S. Zhu, D. J. Yan, J. Polym. Sci. A: Polym. Chem., 38, 4308,(2000).

[27] S. G. Gaynor, S. Z. Edelman, K. Matyjaszewski, Polymer Prepr.,38, 703, (1997).

[28] J. S. Wang, K. Matyjaszewski, J. Am. Chem. Soc., 117, 5614, (1995).

[29] M. Kato, M. Kamgaito, M. Sawamoto, T. Higashimura, Macromolecules, 28, 1721,(1995).

[30] S. V. Arehart, K. Matyjaszewski, Macromolecules, 32, 2221, (1999).

[31] G. Moineau, M. Minet, P. H. Dubois, P. H. Teyssie', T. Senninger, R. Jee'rome, Macromolecules, 32, 27,(1999).

[32] C. J. Hawker, E. Elce, J. Dao, W.Volksen, T. P. Russell, G. G. Barclay, Macromolecules, 29, 2686, (1996).

[33] K. Fila, M. Grochowicz, B. Podkościelna, J. Therm. Anal. Calorim. 133, 489, (2018). 